MLM-MU-90-63-0008

\title{
Process Development Status Report for Advanced Manufacturing Projects
}

John R. Brinkman and Donald A. Homan

March 30, 1990

\author{
RECPUVD \\ JUL 221936 \\ OSTI
}

\section{MOUND}

operated by

EGLE MOUND APPLIED TECHNOLOGIES

P.O. Box 3000, Miamisburg, Ohio 45343-3000

for the

U. S. DEPARTMENT OF ENERGY

Contract No. DE-AC04-88DP43495 


\section{DISCLAIMER}

This report was prepared as an account of work sponsored by an agency of the United States Government. Nelther the United States Government nor any agency thereof. nor any of their employees. makes any warranty. express or implled. or assumes any legal llability or responsibility for the accuracy. completeness. or usefulness of any information. apparatus. product. or process disclosed. or represents that its use would not Infringe privately owned rights. Reference herein to any speciflc commercial product. process. or service by trade name. trademark. manufacturer. or otherwise. does not necessarily constitute or imply its endorsement. recommendation. or favoring by the United States Government or any agency thereof. The views and oplnions of authors expressed herein do not necessarlly state or reflect those of the United States Government or any agency thereof. 
MLM-MU-90-63-0008

\section{Process Development Status Report for Advanced Manufacturing Projects}

John R. Brinkman and Donald A. Homan

Issued: March 30, 1990

\section{MOUND}

operated by

EGEL MOUND APPLIED TECHNOLOGIES

P.O. Box 3000, Miamisburg, Ohio 45343-3000

for the

U. S. DEPARTMENT OF ENERGY

Contract No. DE-AC04-88DP43495 


\section{Foreword}

This is the final status report for the approved Advanced Manufacturing Projects for FY 1989. Five of the projects were begun in FY 1987, one in FY 1988, and one in FY 1989. The approved projects cover technology areas in welding, explosive mațerial processing and evaluation, ion implantation, and automated manufacturing. It is expected that the successful completion of these projects will result in improved quality and/or reduced cost for components produced by Mound. Those projects not brought to completion will be continued under Process Development in FY 1990.

Further information regarding these projects may be obtained from $\mathrm{J}$. R. Brinkman, Component Development Manager, (513) 865-4048, D. A. Homan, Process Technology Development Group Leader, (513) 865-3116, or the appropriate Mound contact identified in each project report. 


\section{Contents}

Page
Pag

MD33001 Laser Welding Data Parameter Acquisition.......... 4

MD33101 Continuous Wire Feed Laser Welding............. 9

MD33201 Advanced Welding Technology.................. 13

MD33301 Processes for Preparing Detonator

Grade Insensitive Explosive Powders................. 21

MD33401 Ion Implantation Processing for

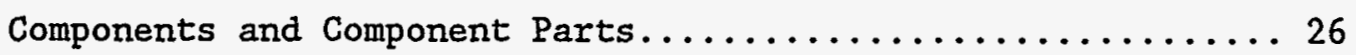

MD33501 Nondestructive Tests to Characterize

Shock Initiated Explosive Pellets................... 30

MD33601 Flexible Manufacturing Systems.............. 36

Summary of FY 1989 Advanced Manufacturing Projects......... 41

Distribution. ............................ 42 


\section{MD33001 Laser Welding Data Parameter Acquisition}

\section{OBJECTIVE}

The original objective of developing a laser welding data acquisition system remained as the project objective. A computer-based data acquisition system will record each laser pulse waveform; then, at the end of the weld, it will analyze each waveform and compare values with acceptance ranges. Data will be retained, based on an exception approach. If all compared values fall within the acceptance limits, the waveform data will be dumped; and the computer will indicate that the weld passed. If the compared values are outside the limits, the waveform data will be stored on a hard disk for additional analysis later. Weld pass-or-fail data can be sent to the mainframe for permanent record storage.

This project will yield two main savings benefits. The product yield will increase because welding problems will be identified immediately by the computer. In some areas, the weld inspection operations will be reduced because of the in-process control feature of the computer data acquisition system. A 28 yield increase in the present laser welding operations at Mound would produce a $\$ 99 \mathrm{~K}$ per year savings.

\section{MILESTONES}

The following is a list of project milestones and the status of each.

1. Procure a development computer system. A number of experiments were performed using the Texas Microsystems XT computer (with the new "Mass Storage" option to the Computerscope) to obtain data and establish the feasibility of the software design approach. These experiments were completed before the software specification was written. The decision to go directly to WR production was driven by the software package cost of $\$ 30 \mathrm{~K}$. The XT computer is much too slow for production applications. The software will be written to run on the high-speed Compaq Deskpro 386 Model 20 computer that is equipped with the optional 80387-20 math coprocessor. One of these computers has been purchased for this program. 
2. Procure commercial software. The Model ISC 16 Computerscope software, with the mass storage option, was purchased from R. C. Electronics, Inc. This software has been used extensively to develop a laser pulse monitoring system and to prove out the concept of approach on the software. This milestone has not changed since the previous status report [1].

3. Develop philosophy for taking and analyzing data. Considerable development work has been completed with the computer and the commercial software to develop this philosophy. Meetings have been held with in-house computer systems personnel, and a meeting was held with an outside software contractor. This milestone has not changed since the previous status report [1].

4. Develop software specification. The software package was divided into three phases: design, software documentation, and debugging. The specification was completed; and a contract was issued to $R$. C. Electronics, Inc. for the software package design. After several design iterations, a 42-page final software package design, which includes the flow chart, formats for all of the screens, and a written explanation of the software needed, was completed. Splitting the design out as a separate phase will save total software package cost because the software logic and options have been very carefully considered and we had a design that can be used by any good software house to document the software.

5. Develop measurement technology. The possibility of developing a method to automatically measure the objective lens to work surface distance had been planned. This distance is presently set up with hard tooling to within \pm 0.002 in. of the desired setting. This procedure has worked well in the past with no indications of welding problems caused by lens-to-work distance. There is now a concern that an automated system for establishing the lens-to-work distance will not be as accurate as the present method, and it may malfunction and cause weld rejects. Consequently, a decision has been made to use 
the present hard tooling procedure, then have the technician make a computer entry of the distance set. The computer will check the welding parameter schedule to verify that the proper setting has been made.

6. Procure software. The 42-page software design was completed February 15, 1989. A RFQ was issued for developing the software package in March 1989. Quotes were received from three software vendors. The quotes varied from $\$ 78$ to $\$ 25 \mathrm{~K}$ with all three vendors capable of producing the software package. The contract was awarded to the lowest bidder. In this case, we felt the lowest bidder was the best qualified for the work. The contract was issued in May 1989. A detailed coordination meeting was held at the start of the contract and at four-to-six week intervals. The initial software was delivered in September 1989.

7. Debug software and hardware. The commerciall software package has been extremely valuable in debugging the hasdware, and hardware debugging will be nearly complete before receipt of the custom designed software. Some of the hardware debugging, however, will require use of the custom designed software. The custom designed software package has been debugged at Mound by the software vendor while running the actual development welding system. The cooperation during the design phase between user and vendor has greatly reduced the debugging phase and enhanced the quality of the software.

8. Develop technology and procedures for calibrating the data acquisition system. Concepts for calibration procedures have been established and integrated into the software design. The calibration hardware was ready and used for the software debugging process. Exact calibration procedures remain to be developed as the software package is used to monitor development welding projects.

9. Use system on several development applications. The software and hardware will be used in FY 1990 to monitor several development 
welding applications. Improvements to both hardware and software will be made based on the results of this effort.

10. Specify a hardware-software system for WR production. Since the decision was made to go directly to the software version that can be used for WR production, implementing this development effort into WR production will occur in FY 1991. Had the original approach been followed, the WR software version would have cost an additional $\$ 15-20 \mathrm{~K}$, considerable hardware and calibration development work would need to be completed and the system would not have been ready for WR production until FY 1992.

\section{ACHIEVEMENTS •}

A 42-page laser data acquisition system software package design was completed. An RFQ was submitted for competitive bids for developing and writing the software program. The vendor was selected; the purchase contract was executed, and five software status reviews were held with the vendor; software debugging was completed onsite. An encoder was selected and purchased for generating weld speed and location data for the computer program. The software program, which was designed for direct WR production application, was delivered and is ready for development welding applications.

The software program and computer hardware system will be completely debugged, and calibration procedures will be developed in the welding development laboratory prior to transfer to a WR production application in FY 1991. The results of this entire effort will be transferred to other DOE sites through the IMOG Joining Subgroup.

\section{PROGRAM STATUS}

This report marks the end of this 3-yr Advanced Manufacturing Project. The effort on this project has established feasibility of the concept and delivered an extremely useful software package that will be used in WR applications. Future work will continue on our Process Development Endeavor, MD311-03 entitled "Weld Data Acquisition." 


\section{REFERENCE}

1. Brinkman, J. R., and D. A. Homan, Process Development Status Report for Advanced Manufacturing Projects, MLM-ML-89-43-0002, EG\&G Mound Applied Technologies (31 March 1989), 46 pp.

\section{MOUND CONTACT}

Further information on this project may be obtained from W. H. Jones, (513) $865-4053$. 


\section{MD33101 Continuous Wire Feed Laser Welding}

\section{OBJECTIVE}

Extremely fast cooling rates and high shrinkage stresses associated with laser welding make the process susceptible to hot cracking. In order to overcome this problem, it is critical that weld fusion zone chemistry be carefully controlled. Presently, this is accomplished in one of two ways. The first involves designing a part to be made of materials that are known to be laser weldable. Unfortunately, this puts a rather severe constraint on the designer because not many metals and alloy combinations are laser weldable in their unaltered states. The problem is even more pronounced in that materials can be deemed to be laser weldable by various development tests but found to be quite unweldable after fabrication into components. Subtle metallurgical changes that take place in certain alloys as a result of heat treating or from reaction with other parts of the component can render even the most weldable of materials unweldable. The second method involves adding a filler washer sandwiched between the two parts to be welded. This involves additional high-precision, lowtolerance machining operations that are not only time-consuming but expensive. The second method also requires the fabrication of an additional part (that is, the filler washer) which necessitates extra paperwork and assembly handling steps such as cleaning. The classical way that hot cracking problems are overcome in gas tungsten arc welding is to add the filler metal directly to the weld fusion zone to control the chemistry. The filler metal is added in the form of a 0.030 to 0.060 in. diameter wire that is continuously fed into the molten pool during fusion to effect the proper fusion zone chemistry. To date, a wire feeder capable of feeding 0.005 to $0.010 \mathrm{in}$. diameter filler wire has not been developed for use with laser welding processes. When such a wire feeder is developed, it will significantly simplify laser welding of crack-sensitive materials, enhance productivity, and result in appreciable cost savings on many programs.

Currently, such components as the MC3478, MC3479, MC3748, and MC3869 incorporate filler washers to make crack-free welds. These components are 
fabricated from materials that are compatible with glass-ceramics both for thermal expansion and interfacial bond behavior. Many components to be made from glass-ceramic headers have been proposed by the design agencies. Strength and hermeticity are the driving factors for the use of this technology. Unfortunately, most alloys that are compatible with glassceramic materials are not laser weldable. This means that all the new glass-ceramic components will probably require some kind of filler washer to make them weldable. A laser welding system incorporating a wire feeder would eliminate the need for filler washers. This technology, if developed, would be applicable to laser welding throughout the weapons complex. It would improve flexibility in many manufacturing processes and save time, manpower, and cost.

\section{MILESTONES}

The following is a list of project milestones and the status of each:

1. Conduct a survey to determine if commercial components are available. It was found that no wire drive assembly or wire delivery assembly is available for wire with a diameter less than 0.020 in. Although a suitable power supply for the wire drive motor has been located, the wire feeder will require special design and development.

2. Determine availability of correct composition and size filler wire. After many phone calls, a spool of 0.006-in. diameter Hastelloy $\mathrm{W}$ filler wire was located and purchased.

3. Develop wire drive concept. A unique wire drive design has been developed for feeding small diameter wire. A prototype system was fabricated and evaluated.

4. Design and fabricate the development wire feeder. The Gem City Engineering Company (in Dayton, $\mathrm{OH}$ ) designed and fabricated the wire feeder; it was delivered in May 1988. 
5. Install and debug wire feeder on the YAG laser welding system in Welding Development Laboratory. The wire feeder has been installed on a Raytheon YAG laser welding system in the development laboratory. The laser control starts and stops the wire feed as part of the total weld cycle. During debugging, it was found that our wire drive concept did not work well. A different approach was incorporated, then the debugging and calibration were completed.

6. Perform preliminary wire feeding tests and evaluate results. Many preliminary samples have been run and evaluated. The results are very encouraging.

7. Evaluate weld joint designs for better wire feeding results. Butt and fillet weld joint designs were fabricated and welded to study weld joint design dimensional requirements. It was found that the wire freezes in the edge of the puddle as each pulse solidifies. This feature was studied with high-speed photography to confirm the theory. This condition means that the wire feed speed must be equal to the surface speed of the weld joint or welding speed. The wire size then becomes a very important welding parameter. Currently, . filler wire, with the following diameters: $0.006,0.008,0.010$, $0.012,0.015$ and $0.020 \mathrm{in}$. is available for development activities.

8. Evaluate welding metallurgy results. Examination of a series of metallurgical samples found predictable results. All metallographic data indicate high quality, good strength laser welds can be expected if proper filler wire is selected for a particular base metal.

\section{ACHIEVEMENTS}

The wire feeding system was integrated with the controls of the laser so that the laser system control starts and stops the feed of wire as part of the total weld cycle. After a thorough evaluation of the new wire feeding system, it was concluded that the original wire drive design concept will not work well for feeding filler wire in the 0.006 to 0.012 in. diameter range. The components for a more conventional design concept, which 
utilizes a drive wheel with a groove for the wire and a flat spring loaded idler wheel, were fabricated, evaluated, and found to work extremely well. A series of samples was welded to evaluate weld joint designs, correlate the relationships between the various laser welding parameters, and feed wire into the weld puddle. High-speed movies were taken to verify theories on the wire feeding process.

WR Lot 2 of the 280586 igniters had to be reworked at Mound to remove solder flux residue from the interior of the igniter that was left by an inadequate cleaning procedure by a vendor. The development wire feeder was used to reweld 135 WR Lot 2 units that were put into stockpile use. Rework of these 135 units at a cost of $\$ 475$ each would not have been possible without the wire feeder and technology developed from this advanced manufacturing project.

The technology for adding filler metal to a YAG laser weld has been developed and is ready for WR applications. Mound is presently designing a wire feeder that will be more suitable for WR production applications. This technology will greatly increase the latitude for weld joint designs, materials, and components normally YAG laser welded. This technology has been transferred to other DOE sites through the IMOG Joining Subgroup.

\section{PROGRAM STATUS}

This report marks the end of a 3-yr program. The project results have been extremely positive. The technology has been well established and has been successfully used on a WR production application. The successful conclusion of this development project will greatly increase component design latitude for future WR production applications.

\section{MOUND CONTACT}

Further information regarding this project may be obtained from W. H. Jones, (513) 865-4053. 


\section{MD33201 Advanced Welding Technology}

\section{OBJECTIVE}

The Advanced Welding Technology proposal was designed to increase process control and reliability of the resistance and gas tungsten arc (GTA) welding processes. The thrust of this project is threefold:

- To develop adaptive (feedback) control of resistance welding processes.

- To develop nondestructive techniques for evaluating pinch welds.

- To develop arc length process control of gas-tungsten-arc, continuous wire-feed (GTACWF) welding systems.

Adaptive (feedback) control system of resistance welding processes would further automate pinch (confined and unconfined) and resistance forge welding operations conducted in fabricating Vineyard and ACORN components. A good control system that controls applied force, electric current amplitude, and/or number of current cycles could further ensure consistency of weld quality and compensate for occasional parameter excursions that would otherwise result in an unacceptable weld or necessitate an SXR (Specification Exception Release) for product acceptance.

The development of nondestructive techniques for evaluating pinch welds is desirable in that the current lack of a meaningful nondestructive test for pinch welds has forced the production sites to rely strictly on process control for product acceptance. Machine qualification consequently requires that large numbers of sample welds be made and destructively analyzed. More important, any excursion in machine performance characteristics or any parameter shifts observed during a pinch weld process may cause the product to be unacceptable, even though the pinch weld itself is perfectly good. Without a reliable way to examine the weld nondestructively, there is no alternative but to rely on process control to ensure weld quality. 
The development of arc length process control of GTACWF welding systems would further automate and enhance the reliability of GTA welding processes. GTACWF welding is performed at Mound for the B61 ACORN program and at other DOE sites for numerous weapons programs. At present, the most advanced equipment still requires that the operator be skilled and exercise great care in making the weld; and, a shift in the welding machine's output could cause the weld to be rejected because of process specifications. Further automation of the welding process (based on feedback control of arc length) would alleviate the problem of rejecting good welds because of process specification tolerances, would simplify the welding operation for the production personnel, and would enhance the reliability of both process and product.

\section{MILESTONES}

The following is a list of project milestones and the status of each:

\section{Adaptive (Feedback) Control of Resistance Welding Process}

a) Design, procure, test, and refine electronic feedback control equipment. The hardware configuration consists of a HewlettPackard 360 computer with two data acquisition units, a 6942 Multiprogrammer, and a 3852 Data Acquisition Control unit. Two data acquisition units allow greater flexibility in the control methods tested and developed. The hardware systems have been debugged and software development is under. way under a data acquisition Process Development Endeavor, MD311-03.

b) Design and conduct a matrix of pinch welding experiments. Experiments were conducted on confined pinch welding of 304L and 21-6-9 materials. With the different data acquisition units, it is possible to interrupt the Pertron weld controller in different ways. When the 6942 Multiprogrammer is used, the computer makes all decisions on interrupts and controls the hardware to halt the weld controller. The 3852 is able to make decisions and interrupt 
the weld controller without the main computer system. Other methods of interrupting the weld controller could be evaluated.

c) Determine the feasibility of using dynamic feedback control of the pinch welding process. Analysis of the control system shows that the objective is possible. Recent progress has significantly reduced the response time of the control system to interact with the Pertron weld controller.

2. Nondestructive Techniques for Evaluating Pinch Welds

a) Explore the possibilities of using pulsed photoacoustic imaging and microfocus $X$-ray radiography to evaluate pinch weld quality. The two techniques have been evaluated with pulsed photoacoustic imaging showing the greatest potential.

b) Identify and purchase image system equipment. Components for the system have been identified, purchased, received, and installed; special fixturing has been designed and fabricated. The system is in the final stages of completion.

c) Obtain system software. Menu-driven imaging and control software was written in-house and is complete.

d) Check out system. Preliminary system alignment, checkout, and initial runs on pinch welds are complete.

e) Evaluate system on actual pinch welds. Although initial results have been very encouraging, better resolution could be achieved by decreasing the step intervals by which the sample probe is translated across the weld from $1.0 \mathrm{mil}$ to a range of 1.0 to $10 \mu \mathrm{m}$. 
3. Arc Length Process Control of Gas-Tungsten-Arc Continuous-Wire-Feed (GTACWF) Welding System

a) Procure and install a basic process control system. The test hardware configuration has been finalized to include a HewlettPackard 310 computer with a 3852 Data Acquisition Control unit. The software, which has proven to be the largest effort in this endeavor, has been tested and improvements continue to be made under the Data Acquisition Process Development Endeavor, MD311-03.

b) Procure and evaluate arc length measurement devices. A commercially available arc length control system, named "Soundtrak," was purchased from Merrick Engineering. Early discussions with Merrick resulted in the marketing of this system, which has been integrated into the development welder.. Since the production condition tests have been run, there have been some unexpected problems with the reliability of the Sound-trak system. The system is sensitive to stray or extraneous noise and appears to be sensitive to atmospheric pressure changes.

\section{ACHIEVEMENTS}

1. Adaptive (Feedback) Control of Resistance Welding Process. A major upgrade of the control system was conducted. The computer system was upgraded to a Hewlett-Packard 360 from the previous Model 220. This is a significant improvement in processor speed, memory, and memory access. The control system was also upgraded with the addition of the 3852 Data Acquisition Control unit. This unit is a "smart" data acquisition system that is capable of making decisions and taking action on its own. The two data acquisition systems are both connected to the main computer. This has allowed greater flexibility in interrupt methods.

A "noise-free" Linear Voltage Displacement Transducer (IVDT), which was procured from Sun Power Co., has been evaluated. In testing, the 
LVDT has proved to be relatively noise-free. The small amount of noise that is seen could possibly be produced by the cyclic thermal expansion of the weld, which corresponds with current flow. Any future work will use the new LVDT. Using the LVDT, it is possible to trigger the weld controller to quit welding within a particular thickness range. An additional noise-free LVDT was received for evaluation. This instrument which is fiberoptic based, should be totally free of induced noise.

Major efforts have centered on interrupt methods and timing. Welds have been interrupted in different stages of completion. Results of weld matrices reported earlier have shown correlations between measurements and bond quality and between length and degree of interface melting. Current methods of interrupting the weld controller have proved very successful.

The time from when the interrupt signal is given to when the controller responds is less than $8 \mathrm{~ms}$. This amount of time equals half a weld cycle and is clearly fast enough. Since its machine code instructs the controller to complete any half cycle started, the half cycle is the shortest time available with this controller. The actual time the computer takes to instruct the controller to terminate the weld is approximately $10 \mathrm{~ns}$.

Further work is now under way on the real-time evaluation of the data acquisition information that precedes the interrupt signal to the weld controller. Various methods of evaluating the weld signals and with different components of the data acquisition system are being investigated to determine the most efficient method.

This project will not be continued under the new Advanced Manufacturing Feasibility Studies. Work has continued, however, on a limited basis with Process Development funding from the Weld Data Acquisition Endeavor, MD311-03. 
2. Nondestructive Techniques for Evaluating Pinch Welds. Pulse-echo and pulse-photoacoustic imaging approaches are being studied as possible means for the nondestructive evaluation of pinch and other types of welds made in-house. Pulse-photoacoustic techniques still appear to be the approach of choice for the evaluation of pinch welds because of the small sampling probe capabilities of the approach and the degree to which acoustic-wave transit times can be measured. Although initial results have been very encouraging, better resolution can be achieved by decreasing the step interval. The sample probe is translated across the weld from $1.0 \mathrm{mil}$ to a range of 1.0 to 10 $\mu \mathrm{m}$. More image enhancement can also be achieved by employing probe-spot overlap techniques, which result in an extremely small effective sampling probe diameter. Conventional pulse-echo approaches are also being reexamined for pinch weld evaluation and include techniques involving: (1) modified through-transmission C-scanning, (2) software-gated data collection, (3) deconvolution of ultrasonic rf A-scans, and (4) digital enhancements of G-scanned images.

A new low-frequency ultrasonic imaging capability has been set up in E-Building dedicated to the evaluation of a variety of welds made in-house. Girth weld samples have been imaged at frequencies up to $30 \mathrm{MHz}$. The images obtained showed great detail in weld structure. A five-axis scanning assembly has been assembled that will extend these evaluation capabilities.

3. Arc Length Process Control of Gas-Tungsten-Arc Continuous-Wire-Feed (GTACWF Welding System. The arc length process control project was to be completed in FY 1989 by finalizing the system response tests and conducting the production condition tests. The production condition tests however, have revealed some unexpected problems. The acoustic arc length control has shown a sensitivity to stray or extraneous noise. This could be an insurmountable problem if two welding systems were located side by side. Also, the feedback control signal appears to be sensitive to variations in atmospheric pressure. The pressure variations within a glovebox system appear to 
cause a control instability. As a result, the acoustic arc length control is sensitive and must be used with care.

This project has developed new methods for the setup and calibration of automatic voltage control systems. Although a superior technology was not found, techniques for optimizing the present technology were developed. Software improvements will continue on the process control system on a limited basis through the Data Acquisition Process Development Endeavor, MD311-03.

\section{RISK ASSESSMENT}

The original risk assessment statement is given below: Every aspect of this proposal has a high risk.factor; that is, the problems to be attacked are very difficult.

1. Further automation of resistance welding by adaptive control appears to be the most promising candidate for success. However, meaningful adaptive control of a process that takes less than $1 \mathrm{~s}$ to complete and involves mechanical as well as electrical responses will not be easy to achieve.

2. Past efforts (very limited) to use scanning laser acoustic microscopy (SLAM) to evaluate pinch welds produced disappointing results. However, everyone involved recognized that the small-scale effort made to "take a quick look" revealed some good potential and made everyone aware that a major and protracted effort would be needed to determine the feasibility of using SLAM for pinch welds.

3. Direct measurement of arc length in a GTA welding process presents an especially difficult task, because a welding arc presents an extremely hostile and unstable environment. The potential benefits from overcoming the problems entailed in directly measuring arc length are so attractive that the risk is eminently worth taking. 
The risk associated with the feedback system is only moderate with the acquisition of the new, faster response time computer. The risk also has been reduced as correlations have been found between weld quality and monitored signals. The benefit of the system is the reduction and/or elimination of rejects or Specification Exception Releases (SXRs). With the modifications made to the system, feedback control to interrupt the weld cycle has been demonstrated to be feasible. Work will continue on a limited basis with Weld Data Acquisition Process Development funding, Endeavor MD311-03.

The nondestructive examination of pinch welds by pulsed, photoacoustic imaging is still proceeding as planned. The equipment tooling and software required for the system are all operational. The initial results are still very encouraging but the indications are that some changes in scanning rates may improve the results. The risk is decreasing as parameters improve and data are reviewed. The ultimate goall is still to nondestructively classify pinch welds into the classes established by destructive metallographic sectioning.

The arc length control project is complete except for software improvements on the process control system. Testing has shown some unexpected problems. The acoustic arc length control is noise and atmospheric pressure sensitive, and we were unable to overcome this problem in the time frame allowed. Although a superior technology was not found for the automatic voltage control (AVC) system, new methods were developed for the set up and calibration of that system.

\section{MOUND CONTACTS}

For further information on the Adaptive (Feedback) Control of Resistance Welding Process, contact R. G. Miller, (513) 865-5141.

For further information on the Nondestructive Techniques for Evaluating Pinch Welds, contact G. Wooten, (513) 865-4656.

For further information on the Arc Length Process Control of Gas-TungstenArc Continuous-Wire-Feed (GTACWF) Welding System, contact E. K. Johnson, (513) $865-4645$. 


\section{MD33301 Processes for Preparing Detonator Grade Insensitive Explosive Powders}

\section{OBJECTIVE}

The objective of this project is to develop processes for manufacturing high purity, insensitive, secondary explosive powders suitable for use in slapper detonators. Current studies include the preparation of fine particle, high surface area TATB (triaminotrinitrobenzene) and HNS (hexanitrostilbene) powders. These powders are needed to support the development and manufacture of mechanically and thermally insensitive slapper detonators that are planned for the future.

\section{MILESTONES AND ACHIEVEMENTS}

TATB is produced in a fine particle form that can be fired in a slapper detonator. The present material, however, requires a large firing set. Methods to further reduce the particle size (that is, increase the surface area) and thus the initiation sensitivity of the pure TATB are being investigated. Surface areas as high as $37 \mathrm{~m}^{2} / \mathrm{g}$ have been achieved. Another approach to increasing the sensitivity of the TATB is to blend it with a secondary explosive such as PETN (pentaerythritol tetranitrate). A mixture consisting of $75 \% 21 \mathrm{~m}^{2} / \mathrm{g}$ TATB and $25 \% 25,000 \mathrm{~cm}^{2} / \mathrm{g}$ PETN was prepared. The mixture fired at $0.858 \mathrm{~J}$ compared to $4.8 \mathrm{~J}$ for the fine powder TATB. Methods have been successful in reducing the high chloride and sulfate levels in TATB by over $70 \%$. However, present purification methods have resulted in an increase in the particle size.

\section{Producing Fine Particle TATB}

Two proven methods are presently utilized to produce fine particle TATB in the submicron range. The first method is based on a process developed by H.H.Cady, IANL. The TATB is dissolved in concentrated sulfuric acid and precipitated out by adding the resultant solution to water. The precipitate is filtered, washed to remove excess acid, neutralized, and freeze dried to recover the fine powder. Mound has developed a continuous precipitation unit for this process. To date over $3000 \mathrm{~g}$ of TATB have been produced by this method. The average BET* surface area of batches produced under various precipitating conditions is $27 \mathrm{~m}^{2} / \mathrm{g}$. 
The second method is based on work performed by R.R. McGuire, LINL. This process involves dissolving the TATB in a DMSO (dimethyl sulfoxide)/ $\mathrm{NaOH}$ solution and precipitating it into a mixture of water and nitric acid. The nitric acid is present to neutralize the sodium hydroxide (NaOH). Seven batches were produced by this method, with an average BET surface area of $28 \mathrm{~m}^{2} / \mathrm{g}$.

The fine particle materials that were produced by both the sulfuric acid and DMSO/ hydroxide methods show an increase in the sulfate and a decrease in the chloride ion concentration levels when compared to the TATB starting material.

*BET - Abbreviation for Brunauer, Emmett, and Teller applied to an equation and method for determing surface area.

Following precipitation, the TATB is collected on a filter media. The substitution of 1 um porosity Teflon filter media for the Nitex (nylon) media, has eliminated digestion of the filter by the acid, allowed for the retention of smaller particles (the filtrate was clear), and reduced the filtration time.

\section{Developing Processes to Produce Fine Particle TATB}

Several additional processes are being investigated. The first involves dissolving the TATB in pure DMSO. At a temperature of $182-185^{\circ} \mathrm{C}$ up to 2.5 wt $\&$ TATB can be dissolved; the TATB can then be recrystallized by adding the resultant solution to water or another nonsolvent. This method has the advantage of eliminating the acids and bases used in the two previous methods. Equipment was purchased but has not yet been adapted to this method. Other solvents, such as sulfalane, are being investigated for use in a process similar to this one.

Fluid energy milling is another possible method. The fluid eriergy mill has no internal moving parts. The size of the particles is reduced when the particles collide in an air vortex. The fluid energy mill has been used at Mound to reduce the size of other explosive powders and is available for development work with TATB in the future. 


\section{Purifying Crude TATB (Starting Material)}

The objective of this project is to provide a TATB that can be used in a detonator. This requires that the TATB be free of impurities and be compatible with detonator materials of construction. The starting TATB has an average chloride ion content of $4550 \mathrm{ppm}$ and a sulfate ion content of 240 ppm. Most of the ionic chloride is in the form of ammonium chloride, which is trapped within the crystal lattice.

Several methods are being investigated to lower the chloride and sulfate ion concentration levels. A vacuum Soxhlet extraction method was used to purify the crude TATB by extraction with DMSO. The chloride level was reduced to $350 \mathrm{ppm}$, but the sulfate level was increased to $1250 \mathrm{ppm}$. This was most likely from residual DMSO. The resultant particle size ranged from 5.40 um $\left(0.2 \mathrm{~m}^{2} / \mathrm{g} \mathrm{BET}\right)$. An extraction using heated DMSO at ambient pressure was also attempted. The chloride level was reduced to $332 \mathrm{ppm}$; however, the sulfate level increased to $2080 \mathrm{ppm}$.

Data from the Pantex Plant indicates that the chloride content can be reduced by water digestion of TATB at elevated temperatures. This method was evaluated on a $500 \mathrm{~g}$ sample using deionized water at $90{ }^{\circ} \mathrm{C}$. The washing was done in a 304 stainless vessel. After about $24 \mathrm{hr}$ corrosion was noted at. the air/liquid interface of the vessel. The corrosion continued with time. The corrosion is attributed to the release of ammonium chloride. Analysis after $70 \mathrm{hr}$ indicated a decrease from 5400 to $3700 \mathrm{ppm}$ in the amount of residual chloride. This method was repeated in a glass vessel with $10 \mathrm{~g}$ of TATB. The TATB was heated to $100^{\circ} \mathrm{C}$ in $2800 \mathrm{~g}$ of water for $216 \mathrm{hr}$ under an argon atmosphere. The chloride ion concentration level of the TATB decreased to $1590 \mathrm{ppm}$.

\section{Purifying Fine Particle TATB}

Several purifications methods are being investigated. Fine particle TATB produced by the sulfuric acid method was dissolved in sulfolane at $150^{\circ} \mathrm{C}$ and thermally recrystallized by very slow cooling $\left(3^{\circ} \mathrm{C} / \mathrm{hr}\right)$ of the resultant solution. Analysis of the samples indicated a $46 \%$ decrease in chloride ion concentration level and a 398 decrease in sulfate ion concentration level. However, the surface area decreased to $0.46 \mathrm{~m}^{2} / \mathrm{g}$. 
Fine particle TATB precipitated via the DMSO/NaOH method was subjected to superheated water at $170{ }^{\circ} \mathrm{C}$. Analyses of the samples indicated a $73 \%$ decrease in the chloride level and a $86 \%$ decrease in the sulfate level. Scanning electron micrographs showed an increase in particle size and hence a decrease in surface area.

An extraction using heated DMSO was used to purify fine particle TATB produced by the sulfuric acid method. The chloride level was reduced $52 \%$. The sulfate level increased 468. Again this method reduced the surface area to $0.2 \mathrm{~m}^{2} / \mathrm{g}$.

\section{Blending TATB with PETY}

A blend consisting of $75 \%$ TATB and 25\% PETN was manufactured for the purpose of evaluation in a slapper detonator to determine initiation sensitivity. It was produced by wet blending high surface area (fine particle) batches. The PETN used was recrystallized from an ethanol/acetone solution by the addition to water. The TATB used was produced by the sulfuric acid process. The blend was manufactured by mixing the preweighed dry powders in water. A high-speed blender provided the agitation and mixing. The blend was freeze dried and screened to recover the dry powder. The Fisher Sub-Sieve Sizer* surface area for the PETN measured $2.52 \mathrm{~m}^{2} / \mathrm{g}$. The BET surface area for the TATB measured $21 \mathrm{~m}^{2} / \mathrm{g}$.

The initiation sensitivity test fire data indicated $0.858 \mathrm{~J}$ were necessary to fire the mixture compared with $4.8 \mathrm{~J}$ to fire fine particle TATB and 108 joules to fire larger particle TATB.

\section{Producing Fine Particle HNS}

The BET surface area range over which the HNS can be recrystallized has been extended from 2.2 to $19.6 \mathrm{~m}^{2} / \mathrm{g}$. This material has been sucessfully fired in a slapper detonator.

\footnotetext{
${ }^{*}$ A method for determing surface area based on the flow of air through a low density compact of the powder.
} 


\section{PROGRAM STATUS}

This project will no longer continue to be funded under the Advanced Manufacturing Projects, but will be continued as an Advanced Development Objective, MD106-02. 


\section{MC33401 Ion Implantation Processing for Components and Component Parts}

\section{OBJECTIVES}

The objectives of this project, as originally stated, are (1) to reduce material processing cost of components, component tooling, and gauging; (2) to reduce material cost for manufacturing component parts and components; and ( 3 ) to expand Mound's capability in the science of material surface chemistry and physics.

\section{MILESTONES}

1. Application of ion beam processing for friction control in electromechanical strong-link components. As a result of information gathered from the literature and from coupon studies conducted by Mound and SNLA, a suitable processing envelope was defined for ion beam processing of detonator safe strong link (DSSL) parts sputterdeposited with a molybdenum disulfide, solid- film lubricant. Candidate DSSL parts have been selected and appropriate workpiece fixturing has been designed to allow both deposition and subsequent ion beam processing. Information gathered to date shows the newly developed technology to be superior to alternate lubricative technologies for friction control in precision electromechanical components. Processed parts will be used in engineering tests and future DSSL builds to evaluate performance.

2. Enhancements of protective hard coatings by ion beam mixing. Previous work conducted at Mound indicated that the surface mechanical properties of titanium nitride hard coatings could be enhanced by ion beam processing. Similar studies are under way with boron nitride hard coats.

3. Enhanced wear resistance and lifetime of tool and die materials. Previously, work was conducted at Mound in association with EMTEC (Edison Materials Technology Center) and Wright State University, to assess the effect of combined titanium and carbon implantation on steels. Results of these studies have shown enhancements in wear resistance of D2 and SAE 1010 steel. A report of this work is expected soon. 


\section{ACHIEVEMENTS}

Since the beginning of this project, much of our effort has been focused on the use of ion beam process technology for the production of integral low friction surfaces in such precision electromechanical components as the DSSL. Initial work was concerned with nitrogen and oxygen ion implantation into titanium alloys. Titanium alloy was used as the wheel material in the MSAD (mechanical safe/arm detonator). The results of the surface analytical studies of the implanted materials have been reported elsewhere [1]. Tribological evaluations were conducted at SNLA (L. E. Pope, Div. 7471).

When the MSAD design was replaced by the DSSL design, experimental plans for surface modification studies were changed to reflect changes in component mechanical design and materials. Sandia researchers had developed a large body of information regarding the dual implantation of titanium and carbon into type 304 stainless steel, and this technology looked promising for further examination. At the same time, there appeared in the literature reports of enhanced performance of molybdenum disulfide films [2]. Thus, the molybdenum disulfide technology was pursued as being the most likely candidate for eventual incorporation into a mechanical strong-link design. A parameter study of ion beam processing of sputter-deposited, molybdenum disulfide solid lubricant films was begun. Sets of 304 stainless steel coupons were sputter-deposited with molybdenum disulfide at Hohman Plating (Dayton, $\mathrm{OH}$ ). The coupon sets were then ion beam processed at Mound, using a matrix of process parameters. The processed sets were delivered to L. E. Pope (SNLA, Div. 7471). Although the coupon sets processed at Mound have not been evaluated, a similar set processed at IANL has been examined. These studies indicate coefficients of friction in the range of 0.02-0.05 are readily attainable within a fairly broad range of ion processing parameters. As a consequence of these very favorable results and quite similar results from the literature, we are continuing development of this technology. Candidate DSSL parts (miniature journal bearings and wire cable) were selected for processing, following discussions with DSSL design engineers. Fixturing was designed and fabricated to allow processing of the parts in the sputtering machine at Hohman Plating 
as well as the ion implanter at Mound, without intermediate handling of process parts. A sufficient number of parts will be fabricated to allow engineering performance tests as well as component parts for the next DSSL design iteration.

In a previous study, MSAD pawls made of 316 stainless steel were coated with titanium nitride and subsequently ion beam processed at $350^{\circ} \mathrm{C}$. The resulting coating, in wear trials conducted at the University of Connecticut, showed enhanced wear resistance and an absence of failure from chipping and spalling of the coating seen in trials of nonimplanted coatings. In order to compare results with the titanium nitride coatings, a similar study is currently under way with boron nitride coatings.

As part of Mound's technology transfer efforts, we have participated in studies of nitrogen implantation into stainless steel and dual implantation of titanium and carbon into both D2 and SAE 1010 steels, with researchers at Wright State University in a project sponsored by EMTEC. Wear evaluations have been conducted at Wright State and at the Materials Laboratory at Wright-Patterson Air Force Base. Results of these studies have shown some enhancements of wear resistance in the ion-implanted materials and a report of the completed work is expected soon. Mound is also participating in some fundamental tribology studies under way at Ohio State University, in collaboration with Dr. David Rigney. Mound will supply implantations of copper into iron coupons and iron into copper coupons.

\section{PROGRAM STATUS}

This project, Ion Implantation Processing for Components and Component Parts, will be continued under the Advanced Development Category MD110-04.

\section{REFERENCES}

1. Barton, B. D., and T. N. Wittberg, Ion Implantation of Two Titanium Alloys, MIM-3603, EG\&G Mound Applied Technologies, Miamisburg, Ohio (August 28, 1989), 27 pp. 
Barton, B. D., T. N. Wittberg, and L. E. Pope, "An Auger Sputter Profiling Study of Nitrogen and Oxygen Ion Implantations in Two Titanium Alloys," Presented at the 11th Symposium on Applied Surface Analysis, Cleveland, Ohio (31 May - 2 June 1989). To be published in Surface and Interface Analysis.

2. Chevallier, J., S. Olesen, G. Sorensen, and B. Gupta, "Enhancement of Sliding Life of $\mathrm{MoS}_{2}$ Films Deposited by Combining Sputtering and High-Energy Ion Implantation," Applied Physics Letters, 48:13, 876-877 (1986).

Kobs, K., H. Dimigen, H. Hubsch, H. J. Tolle, R. Leutenecker, and H. Ryssel, "Improved Tribological Properties of Sputtered MoS Films $_{\mathrm{x}}$ by Ion Beam Mixing," Applied Physics Letters, 49:9, 496-498 (1986).

Kobs, K., H. Dimigen, H. Hubsch, H. J. Tolle, R. Leutenecker, and H. Ryssel, "Enhanced Endurance Life of Sputtered MoS $_{x}$ Films on Steel by Ion Beam Mixing," Materials Science and Engineering, 90, 281-286 (1987). 


\section{MD33501 Nondestructive Tests to Characterize Shock Initiated Explosive Pellets}

\section{OBJECTIVE}

The objective of the project is to develop a nondestructive test to measure a physical property of freestanding, dense, explosive pellets that relates to their initiation sensitivity. These pellets are used in flyer (slapper) detonators or in two-stage explosive components where they are initiated by an explosive shock.

Currently, various physical property measurement methods are being evaluated (for both powder and pellets), with respect to measurable initiation sensitivity of the pellets. As pellets are prepared from explosive powders with a wide range of surface areas and with and without microcoated plastic coatings, a range of properties and initiation sensitivities are exhibited: The method that provides a measurement that relates best to the initiation sensitivity will be identified, developed, and written into a test protocol for use within the DOE complex.

\section{MILESTONES}

The project consists of a number of tasks:

1. Prepare the project plan, solicit ideas from other DOE facilities, and coordinate activities with the staff of the Pantex Plant.

2. Prepare the candidate explosive powders.

3. Characterize the explosive powders.

4. Prepare pellets with various compositions, densities, dimensions, and uniformities.

5. Rank the powders using a simple slapper component. 
6. Evaluate a number of candidate diagnostic tests that measure a property or properties of the pellets.

7. Determine the initiation sensitivity of the materials by test firing the pellets in a slapper test component.

8. Compare the physical test results and the test fire data to determine if a correlation can be established.

9. Prepare a protocol describing the test and its evaluation.

10. Report the results of the project.

To date, the effort has been concerned with Items $1-8$ and 10 ; the project is on schedule with respect to the planned milestones.

\section{ACHIEVERENTS}

The accomplishments to date are as follows:

1. The project working document was prepared and reviewed at LANL (W. H. Meyers and T. E. Larson), at LLNL (H. A. Golopol and W. C. Von Holle), and SNLA (D. E. Mitchel and R. G. Jungst). Valuable suggestions and direction were provided and incorporated into the revised plan. Coordination with the Pantex Plant was maintained through A. A. Duncan, N. O. Rhoton, and G. Locke.

2. Mound has prepared four PETN powders with surface areas of 3470 , $5840,13,300$ and $20,200 \mathrm{~cm}^{2} / \mathrm{g}$ as measured by the Fisher Sub-Sieve Sizer method. It was expected that the shock initiation sensitivity of pellets made from explosive powders would increase with increased surface area of the powder, and the test fire data indicated that this was the case. Additional quantities of the $13,300 \mathrm{~cm}^{2} / \mathrm{g}$ powder were coated with $1 / 4,1 / 2$, and 28 FPC-461, a vinyl chloride trifluorochloroethylene copolymer plastic in order to include the effect of microcoating the powder into the study. 
Microcoating improves the flow properties of the powder, and it also produces stronger pellets. The coating slightly reduces the surface area of the powder, and the test fire results on the pellets show a slight decrease in initiation sensitivity. The data also indicate that higher surface area powders can be used to compensate for the loss in initiation sensitivity caused by microcoating.

Gomputer control of the PETN processing equipment was completed under a Process Development project several years ago. Computer control was also used to prepare the powders for this project. The analysis of the products indicated that under computer control, the processing was very reproducible, and that powders with the desired properties could be obtained by setting the desired parameters before initiating processing.

Pantex has provided four HNS powders that cover a range of surface areas. This material is finer (higher surface area) than PETN and the surface area is measured by the BET method in $\mathrm{m}^{2} / \mathrm{g}$. These powders will be microcoated, characterized, and carried through a complete series of tests similar the ones being conducted on PETN powders.

3. The PETN powders used in the project have been completely analyzed and characterized. This comprehensive analysis and characterization includes: measurement of the surface area, moisture content, solvent content, melting point, decomposition point, impurity content, and particle size and shape. In addition, several particle size distribution methods have been evaluated. One method uses the principle of sedimentation velocity in a fluid and appears to correlate well with the surface area measurement made by the Fisher Sub-Sieve Sịer method. Analysis of the powders has also indicated that explosive material held in a nonsolvent slurry loses some surface area when compared to material that was dried immediately. Other treatments of the powder were found that increase the surface area of the powder and prevent loss of surface area in accelerated aging tests. 
4. The powders were pressed into pellets of various sizes and densities, as appropriate for the test firing or the physical property measurement. The densities ranged from 40 to 958 of the theoretical maximum. The preparation of pellets from the powders indicated that the force required to prepare pellets of a specific density over the range of 1.2-1.7 $\mathrm{g} / \mathrm{cm}^{3}$ increases as the surface area increases (particle size decreases), but it was also affected by the powder bulk density.

5. The powders have been ranked at Mound through the use of a simple slapper initiator component based on a design developed by $W$. Hemsing (IANL). The component used a 0.015 in. wide DeCokker, a 1/8-oz copper bridge, a 0.001 in. thick Kapton flyer, and a barrel of 0.012 in. in diameter and $0.007 \mathrm{in}$. in length. The data from the ranking test were found to correlate very well with the data obtained in the test fire matrix, which is described in the next section of this report. The ranking test can be used to provide, easily and quickly, an indication of how the surface area of the powder would affect initiation sensitivity. The data indicate, that for this slapper configuration, the lowest surface area material $\left(3470 \mathrm{~cm}^{2} / \mathrm{g}\right)$ is the least sensitive. The other three powders are much more sensitive with all fitting a predictable linear relationship.

The test-fire matrix for characterizing the initiation sensitivity of the PETN powders was completed. The detonators were prepared by the flexible tape process, using 2-mil thick Kapton with four different bridge sizes: $7.5,12.5,17.5$, and $22.5 \mathrm{mils}$. A square bridge was. used to simplify modeling of the system. A barrel, the same diameter as the bridge width, was sized to maintain a $1: 1$ length-to-diameter ratio. The four uncoated PETN powders and the three microcoated powders were all tested. The test fire results proved the validity of the powder selection as a model for validating the characterization protocols. A range of shock initiation sensitivities was achieved to include a linear region and, as well, thresholds where dramatic changes in sensitivity occur. In addition, sensitivity was controlled by inactivating the surface area effects through the 
addition of thin layers of plastic to the explosive crystals. A complex set of data was created, which if confirmed by a candidate method, would prove its validity.

6. Seven candidate test methods are being evaluated. Several of the methods - X-ray imaging, ultrasonic pulse attenuation and microwave absorption spectroscopy - provide information that is difficult to interpret and the results do not appear to correlate with pellet sensitivity. The laser shock impedance measurements and the laser holographic interferometry methods are in the early stages of evaluation. Initial work indicates that these methods may provide useful information. The enhanced pressure drop analysis is an extension of the Fisher Sub-Sieve Sizer method. This measurement method is typically used on pellets of 0.4 to 0.8 porosity. The method is being extended to measure the air flow through more dense (lower porosity) pellets. A theoretical computer study was conducted using the equations that apply to the Fisher method to determine if the method could provide useful data if the total pressure was raised or the thickness of the powder compact was reduced. A component is being constructed to test this theory. Even though the Fisher method is generated from a compact of the powder at much lower densities than in a typical pellet, the data do correlate with the initiation sensitivity of the pellets in the test fire series.

7. At the present time, the initiation sensitivity ranking test and the Fisher Sub-Sieve Sizer method provide data that can be correlated with the initiation sensitivity of the pellets based on a comprehensive test fire series. However, the ranking test is destructive and the Fisher method is performed on a low density compact of the powder. As a result, both methods have undesirable features, and other methods will continue to be evaluated in anticipation of meeting most of the proposed test features. 
8. Later in the program, the test protocol will be prepared, and the test procedure will be verified.

9. The reporting requirements have been and are being satisfied as required by the project plan. :

\section{PROGRAM STATUS}

The project will be continued under the Advanced Manufacturing Feasibility Studies, Endeavor MD313-01.

\section{MOUND CONTACTS}

Further information on this project can be obtained from W. R. Feairheller, (513) 865-4487 or G. L. Ball (513) 865-4036. 


\title{
MD33601 Flexible Manufacturing Systems
}

\author{
Part I - Pyrotechnic Component Fabrication System
}

\section{OBJECTIVE}

The purpose of this project is to develop an advanced manufacturing cell for the fabrication of pyrotechnic components. The system will start with a fully machined header and take it through the appropriate process steps to produce a completely fabricated and tested pyrotechnic component. AII parts assembly, attachment, gauging, and inspection processes will be done by the manufacturing cell along with full computer acquisition of the data. Since all operations will be performed within the process flow of the manufacturing cell concept, all travellers and other quality assurance paperwork will be electronically handled by the system control computers. This has many advantages over present systems in that it will provide a complete, real-time, coherent manufacturing database for every critical operation on every part handled by the system. This concept lends itself extremely well to optimizing fabrication processes through the use of statistical process control (SPC).

\section{MILESTONES}

Feasibility studies were planned for FY 1989 to determine whether appropriate technologies and equipment exist for advancing to phase II in FY 1990. Process flow of existing manufacturing lines was to be reviewed in detail and specific parts of the processes were to be examined in great detail to see if it would be feasible both technically and economically to automate these processes. A decision on whether automation and integration are feasible was to be made at the end of FY 1989. If feasible, then procurement of necessary funds, technologies, and equipment will begin in FY 1990 during phàse II. Procurement will continue through FY 1991 along with integration of the processing system with the data acquisition hardware and software. This work will continue into FY 1992 along with system checkout and the start of process development for specific WR products. 
The aforementioned are the global perspectives of a fully automated and fully integrated flexible manufacturing cell for electroexplosive components. During the first part of the feasibility studies performed in FY 1989, it became apparent that there are several key areas in the processing of pyrotechnic components which were labor intensive and could be automated while keeping the separate parts of the process flow and not integrating the entire system. Automating of these separate processes would be of great benefit to the overall productivity of the entire process. Furthermore, if automated with integration in mind, the separate processes could be designed in such a way as to lend themselves to a standard of integration at a later date. This would ultimately achieve the overall global goals of a fully automated and integrated manufacturing system. Phase $I$ is progressing in this manner.

\section{ACHIEVEMENTS}

The fabrication processes of 13 pyrotechnic components have been reviewed for common processes and identification of unique and constrained processes. These components represent both in-house and vendor-procured production. A generic process flow has been developed, and specification sheets for some of the processes have been assembled. The generic process flow addresses both material flow and data flow.

Several meetings with SNLA (Division 1414) personnel were held and the applicability of their robotic program was reviewed. The level of sophistication attained at SNLA will help in the implementation of this - project. Several robotic concepts were modeled by SNLA with iterative input from Mound project engineers. These studies have significantly aided in the conceptualization of this project.

Mound product, development, data acquisition and robotic personnel, and SNLA design and robotic personnel reviewed the generic process flow for areas that would benefit from automation and that are feasible. The conclusion is that the pyrotechnic loading process is the most likely candidate for immediate consideration, and work on this process is compatible with the overall prospect of integrating the loading station into the larger project of an automated assembly line. 
FY 1989 activities centered around reviewing the technologies required for the loading station. These technologies include part identification, weighing, and the real product requirements for part loading with respect to specified and required performance. From this review, a loading concept has been formulated, and a prototype model has been fabricated. The concept includes a universal tooling design that allows for rapid change out of in-process product tooling to another product in a reasonable period of time. The model was examined and critiqued by Mound and SNLA personnel. A plan was then formulated for obtaining two sets of prototype tooling hardware which incorporated some of the changes from the review process. One set of hardware will be used to perform parametric loading studies on energetic powders at Mound, and the other set will be used to test robotic loading integration at SNLA. When these studies have been completed, the SNLA robot will be brought to Mound and integrated into the energetic material loading system and checked out on real components. There may still have to be a perfornance study undertaken to resolve certain details when it is determined what processing limits can be attained.

\section{PROGRAM STATUS}

The original justification for this project still remains valid. The main benefits of a system like this will be in the areas of increased productivity, better quality assurance and statistical process control. Increased productivity would result from the displacement of nearly all of the labor-intensive tasks presently being done. This system would also handle very effectively, efficiently and accurately the time-consuming and burdensome WR paper processing attendant with producing WR product. This concept has great potential benefit throughout the weapons complex. What we learn in this endeavour can be directly translated to many production processes around the complex.

This project will be continued as an Advanced Manufacturing Feasibility Study under Objective, MD313-02. 
Part II - Flexible Circuit Tape Processing

\section{OBJECTIVE}

The objective of this part of the project is to upgrade the flexible circuit tape processing facility with higher efficiency equipment. Such an upgrading would result in a more automated, less labor-intensive operation and increase the capacity for production. The following section on program status includes some of the technologies being considered for use in the upgrade:

\section{PROGRAM STATUS}

\section{Continuous Covercoat Lamination}

Since there is no continuous laminating press available commercially, Mound is developing its own design. The press has been designed, a patent has been applied for, and the prototype has been built and is functioning. Preliminary data from the prototype indicate a time saving of 558 for laminating parts with the realization of continuous automatic operation. This work will be continued under Advanced Manufacturing Feasibility Studies Objective, MD313-04.

\section{Kapton Etching}

This is still a viable option, although ES\&H (Environmental Safety and Health) considerations may prevent fruition. This work will be continued under Advanced Manufacturing Feasibility Studies Objective MD31305.

\section{Integral Cable/Bridge Fabrication.}

Integral cable/bridge circuits have been plated in a commercial shop with good results. The next step is to design and obtain a reel-to-reel system that is tailored to specific needs.

\section{Selective Kapton Removal Using an Excimer Iaser}

Through developmental studies, the excimer laser has been shown to be more efficient at Kapton removal than is the present $\mathrm{CO}_{2}$ laser system. The work was performed using an in-house excimer. A more rugged, production excimer has been ordered and will be installed in the production process during FY 1990. 
Automatic Registration Hole Punching

A new punching system has been ordered. The controlling software, reel-to-reel tape transport system, and video equipment have been developed and are available for assembly to the punching system. The punching system has been assembled and is presently undergoing final system checkout prior to being installed into the flexible circuit area. This system will see further development efforts and subsequently be integrated into the flexible circuit manufacturing process.

Wes Process Regeneration/Rejuvenation

All new incoming wet process equipment will be equipped with these systems. Preliminary work is under way to determine the optimum parameter settings. Upon receipt, April 1990, the equipment will be adjusted for the proper parameter settings.

\section{Automatic Excimer Kapton Removal with Aperture Imaging}

No work is presently in progress on this project. It will start after the new excimer has been installed and is in routine use.

Wet Processing Using Automatic Solution Monitoring and Control This will be the next step after the regeneration/rejuvenation systems are working in the production area. Incoming new equipment is being equipped with monitoring equipment and/or ports to facilitate this installation. The equipment will be installed in April 1990. The installation will also include a data recording. and monitoring computer that will record the daily operations after an initial parametric evaluation to establish parameter settings.

\section{Conductive Adhesive for Bridge Attachment}

Work has been progressing on this project with very good results. Slapper components built and tested using conductive adhesives have been shown to be as good as units fabricated by welding bridges in place. The influence of long-term aging on the performance of units fabricated using conductive adhesives needs to be determined. This work will be continued under Advanced Manufacturing Feasibility Studies Objective, MD313-06. 


\section{Summary of FY 1989 Advanced Manufacturing Projects}

\begin{tabular}{|c|c|c|c|c|c|}
\hline \multirow{2}{*}{$\begin{array}{c}\text { Project } \\
\text { No. } \\
\end{array}$} & \multirow[b]{2}{*}{ Project Title } & \multicolumn{2}{|c|}{ FY89 Planned } & \multicolumn{2}{|c|}{ FY89 Actual } \\
\hline & & $\underline{D . M Y}$ & $\underline{\mathrm{T} . \mathrm{SK}}$ & D.MY & $\underline{\$ \mathrm{~K}}$ \\
\hline MD33001 & Laser Welder Parameter & 1.0 & 148 & 1.1 & 160.2 \\
\hline . & Data Acquisition & & & & \\
\hline \multirow[t]{2}{*}{ MD33101 } & Continuous Wire Feed & 0.5 & 74 & 0.6 & 81.8 \\
\hline & Laser Weld System & & & & \\
\hline \multirow[t]{2}{*}{ MD33201 } & Advanced Welding & 1.5 & 221 & 1.5 & 216.2 \\
\hline & Technology & & - & & \\
\hline \multirow[t]{4}{*}{ MD33301 } & Process for Preparing & 1.5 & 221 & 1.7 & 262.4 \\
\hline & Detonator Grade & & & . & \\
\hline & Insensitive Explosive & & & & \\
\hline & Powder & & & & . \\
\hline \multirow[t]{4}{*}{ MD33401 } & Ion Implantation & 1.0 & 148 & 1.0 & 146.0 \\
\hline & Processing for & & & & \\
\hline & Components and & & & & \\
\hline & Component Parts & & & & \\
\hline \multirow[t]{4}{*}{ MD33501 } & Nondestructive Tests & 2.0 & 295 & 2.0 & 301.7 \\
\hline & to Characterize Shock- & & & & \\
\hline & Initiated Explosive & & & & \\
\hline & Pellets & & & & \\
\hline \multirow[t]{3}{*}{ MD33601 } & Flexible Manufacturing & 1.4 & 207 & 1.0 & 145.7 \\
\hline & Systems & 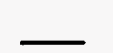 & - & 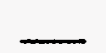 & 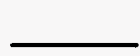 \\
\hline & TOTAL & 8.9 & 1314 & 8.9 & 1314.0 \\
\hline
\end{tabular}




\section{Distribution}

EXTERNAL

G. N. Pappas, POD/AL (14)

J. A. Morley, DOE/DAO (2)

INTERNAL

G. L. Ball

B. D. Barton

J. R. Brinkman (5)

T. L. Buxton

R. J. DeSando

J. V. Dichiaro

W. Feairheller

R. A. Fischbein

L. D. Haws

D. A. Homan

G. L. Houston

C. W. Huntington

E. K. Johnson

W. H. Jones

D. P. Kelly

J. R. McDougal

D. E. Michel

G. D. Miller

W. H. Smith

R. F. Salerno

R. Thorpe

R. E. Vallee

C. M. Woods

Publications

Document Control (3) 